also an important element to establish evacuation centers effectively.

Prehosp. Disaster Med. 2019;34(Suppl. 1):s93-s94

doi:10.1017/S1049023X19001936

\section{Hunger in Latin America: What Can We Do?}

Dr. Silvana Dal Ponte ${ }^{1}$, Mrs. Daniel Menezes ${ }^{2}$

1. Hospital De Clínicas De Porto Alegre-brazil, Porto Alegre, Brazil

2. DMZ Sport Food Restaurant, Porto Alegre, Brazil

Introduction: Hunger is a global problem and has increased in recent years. In Latin America, hunger continues in high numbers. Although the level of hunger is relatively low compared to other regions, this increase in Latin America is mainly explained by the economic slowdown in South America. Also, climate changes are already weakening the production of the main crops in tropical and temperate regions.

Aim: Report the numbers of hunger in Latin America.

Methods: A cross-sectional study with reports of the World Health Organization's hunger figures, September 2018.

Results: The number of hungry people in the world has increased for the third consecutive year and affects 821 million people, according to a report released by UN agencies. This corresponds to one in nine people in the world. In Brazil, the figures indicate that more than 5.2 million people spent a day or more without consuming food by 2017, which corresponds to $2.5 \%$ of the population. In Latin America and the Caribbean, hunger has also increased and affects some 39 million people. Discussion: Hunger is a catastrophic problem in Latin America. Involving professionals in food and nutrition to try to reduce these numbers appears to be a good strategy because just as the doctor treats the disease, the involvement of other specialists to address the cause of the problem can bring long-term benefits. A social project for this purpose that mobilizes chefs and nutritionists is in progress in Brazil.

Prehosp. Disaster Med. 2019;34(Suppl. 1):s94

doi:10.1017/S1049023X19001948

Measuring the Health Impact of Natural Disasters - The Attribution Challenge Facing the Medical Community

Dr. Gerard A Finnigan

School of Medicine, Deakin University, Highton, Australia

Introduction: Published reports on health impacts from natural disasters causing injuries, poisonings, infectious disease, chronic illness, and NCDs continue to grow exponentially. Simultaneously, calls for the improvement in scientific rigor to improve causal links, strength of association, and efficacy of interventions are increasing. At the heart of this challenge is demonstrating mortality and morbidity risk across a time continuum, where the health effect is not detected for weeks, months, or years after the disaster event. In some circumstances, the presence and acuity of illness are not apparent until after an insidious or cumulative point has been reached. Notwithstanding medical observations or disaster-attributed morality classification matrices being available for 20 years, natural disaster mortality continues to be measured narrowly, on those confirmed dead (acute physical trauma, drowning, poisoning, or missing). There has been little effort to expand mortality assessment beyond this historical lens. For example, it fails to consider suicide in drought and was not redefined when the Indonesian fires caused the highest mortality in 2015. Tens of thousands of lives were lost from smoke exposure.

Aim: This study sought to test the progress of two decades of published medical and scientific literature on natural disaster mortality reporting.

Methods: A retrospective analysis of natural disaster impact reports for the past ten years was performed on three of the world's largest disaster databases, including CRED, Sigma, and ADRC.

Discussion: WADEM members must commence a strategic process to expand the recognition of health impacts from natural disasters. Global and domestic advocacy is required for building evidence through improved systematic collection of data and especially reporting patient continuum of care as a minimum standard. Without this leadership, disaster health impacts will continue to be underestimated and emergency health program responses and financial resources will fall short in protecting those most at risk.

Prehosp. Disaster Med. 2019;34(Suppl. 1):s94

doi:10.1017/S1049023X1900195X

\section{Risk of Retrogression in Social Rights and Reduction of Brazilian Public Policies A/Prof. Maria Isabel Barros Bellini, Sr. Rodollfo de Bellini e Soares ${ }^{2}$ \\ 1. Pontifícia Universidade Católica, Porto Alegre, Brazil \\ 2. Escola De Saude Pública, Porto Alegre, Brasil}

Introduction: Brazil has 200 million descendants of African, Portuguese, Indigenous, German, Italian, and other peoples who have built their identities. The Federal Constitution was rewritten in 1988 to include a Social Protection System. Between 2000 and 2016, the federal government was governed by the Workers' Party. This party invested in the creation of inclusive public policies and affirmative actions built through collective processes of citizenship that guaranteed better living conditions for the population. In one decade, it went from being underdeveloped to developing. In 2016, the elected president of the Workers' Party was withdrawn from power through impeachment. In the next election, right-wing conservatives excluded speech, attacked minorities (e.g. LGBT population), and defended the traditional family.

Aim: To understand the retreat of Brazilian public policies in a country that set public social policies, compensatory policies, and affirmative actions guaranteeing citizenship of men and women.

Methods: Qualitative research with analysis and reflection on the regression of universalist public policies and affirmative policies with the creation of quotas.

Results: The creation of affirmative actions was guaranteed. Vacancies in public tenders for the black population led to the establishment of 50\% quotas for blacks in universities, and the creation of a universal health system, or universal expanded 
health indicators. The federal government created a group of SUS analysis by reducing actions.

Discussion: Social inequality in Brazil is one of the worst in the world. 16 million people live below the poverty line (OXFAM, 2017). In recent decades, the population that was expanding and strengthening access to services, health, education, and social assistance network has seen a reduction of public policies. The importance of research that points to this reduction of rights is fundamental for documenting what has already been achieved.

Prehosp. Disaster Med. 2019;34(Suppl. 1):s94-s95

doi:10.1017/s1049023x19001961

\section{The Social Determinants of Health in Disaster Risk Reduction} Mr. Joseph Cuthbertson ${ }^{1}$, Professor Frank Archer ${ }^{1}$, Dr. Jose Rodriguez-llanes ${ }^{2}$, Dr. Andrew Robertson ${ }^{3}$

1. Monash University

2. European Commission Joint Research Centre Directorate of Sustainable Resources, Food Security Unit

3. Western Australian Health Department

Introduction: The rationale for undertaking this study was to investigate how characteristics of population health relate to and impact disaster risk, resilience, vulnerability, impact, and recovery. The multi-disciplinary environment that contextualizes disaster practice can influence determinants of health. Robust health determinants, or lack thereof, may influence the outcomes of disaster events affecting an individual or a community. Aim: To investigate how the social determinants of health inform community perceptions of disaster risk.

Methods: Community perception of disaster risk in reference to the social determinants of health was assessed in this study. Individual interviews with participants from a community were conducted, all of whom were permanent community residents. Thematic analysis was conducted using narrative inquiry to gather firsthand insights on their perceptions of how characteristics of population health relate to and impact an individual's disaster risk.

Results: Analysis demonstrated commonality between interviewees in perceptions of the influence of the social determinants of health on individual disaster risk by determinant type. Interviewees sensed a strong correlation between low community connection and disaster risk vulnerability. Specific populations thought to have low community connection were perceived to be socially isolated, resulting in low knowledge or awareness of the surrounding disaster risks, or how to prepare and respond to disasters. In addition, they had reduced access to communication and support in time of need.

Discussion: The importance of a strong social community connection was a feature of this research. Further research on how health determinants can enable disaster risk awareness and disaster risk communication is warranted.

Prehosp. Disaster Med. 2019;34(Suppl. 1):s95

doi:10.1017/S1049023X19001973 